\title{
Study on the contamination of Abadan public parks soil with Toxocara spp. eggs
}

\author{
Sharif Maraghi ${ }^{1}$, Komeil Mazhab Jafari ${ }^{2,3^{*}}$, Seyed Mahmoud Sadjjadi ${ }^{4}$, Seyed Mahmoud Latifi ${ }^{5}$ and Mohammad Zibaei $^{6}$
}

\begin{abstract}
Background: Toxocariasis is one of the most important zoonotic diseases caused by Toxocara larva stage in humans. One of the major transmission routes of infection, especially in children is pica. The aim of this topic was study the contamination of Abadan public parks with Toxocara eggs.

Materials and methods: Two hundred and ninety one samples of soil were collected from 31 parks. The samples were examined for Toxocara spp. eggs by modified floatation method using saturated sucrose. The results were analyzed using SPSS version 19 and Chi-square test.

Results: Eighty five (29.2\%) out of 291 samples were infected with Toxocara spp. eggs, means19 (61.2\%) of the 31 parks were contaminated. There was no significant difference between the urban and suburb parks contamination ( $p=0.208$ ) but there was significant relation between contamination with Toxocara spp. eggs and traces of cats and dogs presence in the parks $(p=0.001)$.

Conclusion: As the contamination of Abadan public parks soil with Toxocara spp. eggs is relatively high, the people and specially children might get the contamination during stay in the parks and measures should be taken to control the stray cats and dogs.
\end{abstract}

Keywords: Toxocaraiasis, Toxocara, Contamination, Park, Soil, Abadan, Iran

\section{Background}

Toxocariasis is a zoonotic disease caused by Toxocaracanis and Toxocaracati Larvae in humans. Infection acquire via the ingestion of infective ova with vegetables or pica or by ingesting products of contaminated paratenic hosts [1-3]. The larva hatch in small intestine and immigrates to other organs, almost to liver and cause visceral larva migrans (VLM) or localizes in eyes and causes ocular larva migrans (OLM) [4-7].

Although dogs and cats are definitive hosts, but the expelled eggs should remain in the soil until larva develops within 6 week $[5,6]$. The infection of dogs and cats in Iran was proved by Epidemiological surveys [8-11].

Examination of Urmia public parks soil indicated that $7.8 \%$ of the parks were contaminated with Toxocara eggs [12], In Khoramabad 22.2\% [13], In Tehran 38.7\% [14], and in Shiraz 6.3\% [8].

\footnotetext{
* Correspondence: k.mjafari@yahoo.com

${ }^{2}$ Abadan school of Medical sciences, Abadan, Iran

${ }^{3}$ Ahwaz Jundishapur University of Medical Sciences, Ahwaz, Iran

Full list of author information is available at the end of the article
}

The aim of this topic was study the contamination of Abadan public parks soil with Toxocara eggs.

\section{Materials and methods}

From January to April 2012, 291 soil samples were collected from 31 Abadan public parks of urban and suburb of Abadan southwest Iran. Each sample was 100 grams of soil with $3 \mathrm{~cm}$ ground depth. The samples were examined for Toxocara spp. using Zibaei et al. method [15]. We modified the method by replacement of sieve with mesh material and using saturated sucrose (1.2 $\mathrm{g} / \mathrm{cm} 3)$. In this method, each soil sample was grinded and dissolved in distilled water, mixed well and filtered by 3 layers of mesh material, then centrifuged in $2000 \mathrm{rpm}$ for 5 minutes and supernatant was discarded and precipitation was re-suspended in normal saline. Then it was centrifuged again and the supernatant was discarded and precipitation was removed by shaking the tube and saturated sucrose was added and centrifuged in $1500 \mathrm{rpm}$ for 15 minutes and then sucrose was added to filling the top of the tube. Then the coverslip was placed on the tube in

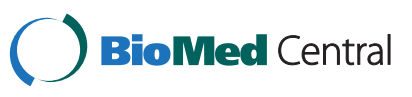



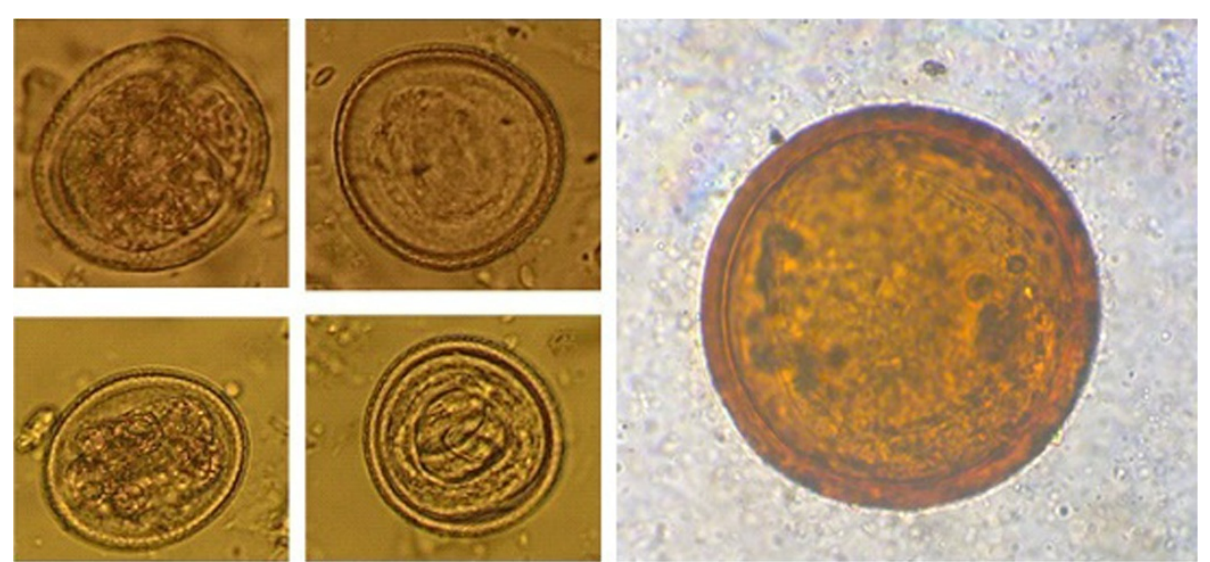

Figure 1 Eggs of Toxocara Species isolated from the soil of Abadan parks (400x).

touch with the sucrose and was kept in the rack for 45 minutes, and then the coverslip was removed and placed on a glass slide and studied under the light microscope.

\section{Results}

Eighty five (29.2\%) out of 291 samples were positive for Toxocara spp. eggs (Figure 1). The eggs were isolated from 19 (61.2\%) parks. 23.7\% of contaminations were in urban parks and $5.5 \%$ in suburban.

There was no significant difference between the contamination in urban and suburb $(\mathrm{p}=0.208)$, but the contamination in parks where the pets were present was higher $(\mathrm{p}=0.0001)$.

\section{Discussion}

Soil transmitted and zoonotic helminthes are still one of the most important health problems in the world, ever in developing countries [16].

In this study the rate of soil contamination with Toxocara spp. egg in Abadan in south west Iran was 29.2\%. The eggs were isolated from $61.2 \%$ of the parks.

In this study the sieve was replaced by application of mesh material which caused the water saving and accelerating the method and more eggs could be achieved.

The contamination in our study was lower than other reports such as Greece (97.5\%), Germany (89.1\%), Japan (63.3\%), Brazil (60\%), Malaysia (54.5\%), and Cuba (42.2\%) [17-22].

The rate of contamination was higher than reports from USA (20.6\%), Turkey (18.9), Iraq (15.5), London (6.3\%) [23-26], Shiraz 6.3\% [8], Ireland 5.6\% [27], Urmia $3.9 \%$ [12], and Spain 1.2\% [28].

The difference of contamination rate depends on culture, climates, methodology of examination and sample collection. Recent reports by Khazan et al. [29] and Tavalla et al. [14] indicated that the rate of Tehran soil contamination was $10 \%$ and $38.7 \%$ respectively; surprisingly the samples of both studies were collected in 2008.

Serological surveys with ELISA and Western blot techniques in hypereosinophil individuals in ahwaz indicated that $19 \%$ of them were positive for toxocariasis [30]. Talaizadehet all reported 3 cases of toxocariasis in pathology and serological examination [31].

As the rate of infection with Toxocara species in dogs is varied from 10 to $51.6 \%$ [32,33] and in cats from 13 to $52.7 \%[10,34]$ and the pets have access to the parks, the rate of soil contamination in many parks in Iran is high $[13,14]$.

\section{Conclusion}

The result of this study indicated that the rate of soil contamination of Abadan public parks with Toxocaras pp. eggs is relatively high and measures should be taken to control the presence ofstray dogs and cats in Abadan.

\section{Competing interests}

The authors declare that they have no competing interests.

\section{Authors' contributions}

KMJ collected the samples. SM, SMS and MZ carried out the examination of the samples. SML carried out the analysis of the data. All authors read and approved the final manuscript SM, KMJ, SMS, SML, MZ.

\section{Acknowledgements}

This article is issued from the M. Sc. Thesis of Mr. Komeil MazhabJafari (B- 90/ 0012) and financial support was provided by Ahwaz Jundishapur University of Medical Sciences which is fully acknowledged.

\section{Author details}

'Department of Parasitology and Mycology, Abadan Arvand International division, Institute of Health, Thalassemia and Hemoglobinopathy Research Center, Ahwaz Jundishapur University of Medical Sciences, Ahwaz, Iran.

${ }^{2}$ Abadan school of Medical sciences, Abadan, Iran. ${ }^{3}$ Ahwaz Jundishapur University of Medical Sciences, Ahwaz, Iran. ${ }^{4}$ Department of Parasitology and Mycology, School of Medicine, Shiraz University of Medical Sciences, Shiraz, Iran. ${ }^{5}$ Department of Biostatistic and Epidemiology, School of Health, Health research institute, Diabetes research Center, Ahwaz Jundishapur University of Medical Sciences, Ahwaz, Iran. ${ }^{6}$ Department of Parasitology and Mycology, School of Medicine, Alborz University of Medical Sciences, Karaj, Iran. 
Received: 7 July 2013 Accepted: 26 April 2014

Published: 19 May 2014

\section{References}

1. Schantz PM: Toxocaralarva migrans now. Amer J Trop Med Hyg 1989, 41:21-34

2. Despommier D: Toxocariasis: clinical aspect, epidemiology, medical ecology, and molecular aspects. ClinMicrobiol Rev 2003, 16:265-272.

3. Azizi S, Oryan A, Sadjjadi SM, Zibaei M: Histopathologic changes and larval recovery of Toxocaracatiin experimentally infected chickens. Parasitol Res 2007, 102:47-52

4. Glickman LT, Schantz PM: Epidemiology and pathogenesis of zoonotic toxocariasis. Epidemiol Rev 1981, 3:230-250.

5. Coelho LM, Dini CY, Milman MH, Oliveira SM: Toxocara spp. eggs in public squares of Sorocaba, Sao Paulo state, Brazil. Rev Inst Med Trop Sao Paulo 2001, 43:189-191.

6. Chorazy ML, Richardson DJ: A survey of environmental contamination with ascarid ova, Wallingford, Connecticut. Vector Borne Zoonotic Dis 2005, 5:33-39.

7. Dubná S, Langrová I, Jankovská I, Vadlejch J, Pekár S, Nápravník J, Fechtner J: Contamination of soil with Toxocaraeggs in urban (Prague) and rural areas in the Czech Republic. Vet Parasitol 2007, 144:81-86.

8. Motazedian H, Mehrabani D, Tabatabaee SH, Pakniat A, Tavalali M: Prevalence of helminth ova in soil samples from public places in Shiraz. East Mediterr Health J 2006, 12(5):562-565.

9. Eslami A, Mohebali M: Parasitisme des chencs de bergers et implication en sante public en Iran. Bull Pathexot 1988, 81:94-96.

10. Zibaei M, Sadjjadi SM, Sarkari B: Prevalence of Toxocaracatiand other intestinal helminths in stray cats in Shiraz, Iran. Trop Biomed 2007, 24:39-43.

11. Razmi G, Sardari K, Kamrani A: Prevalence of Echinococcusgranulosus and other intestinal helminthes of stray dogs in Mashhad area, Iran. Archives of Razi Institute, Autumn 2006, 61(3):143-148.

12. Tavassoli M, Hadian M, Charesaz S, Javadi S: Toxocara spp. eggs in public parks of Urmia City, West Azerbaijan Province Iran. Iranian J Parasitol 2008, 3:24-29.

13. Zibaei M, Abdollahpour F, Birjandi M, Firoozeh F: Soil contamination with Toxocara spp. eggs in the public parks from three areas of Khorram Abad, Iran. Nepal Med Coll J 2010, 12(2):63-65.

14. Tavalla M, Oormazdi H, Akhlaghi L, Razmjou E, MoradiLakeh M, Shojaee S, Hadighi R, Meamar A: Prevalence of parasites in soil samples in Tehran public places. Afr J Biotechnol 2012, 11(20):4575-4578.

15. Zibaei M, Uga S: Contamination by Toxocaraspp. eggs in sandpits in Kobe, Japan. J Environ Control Tech 2008, 26(2):32-37.

16. Alonso JM, Stein M, Chamorroo MC, Bojanich MV: Contamination of soi with eggs of Toxocara in a subtropical city in Argentina. 1 Helminthol 2001, 75:165-168.

17. Himons C, Antoniadou-Sotiriadou K, Fry- das S: Research survey on the prevalence of Toxocara ova in the soil of public parks in Thessaloniki. Helliniki-Tatriki 1992, 58(5):333-339.

18. Duvell D: The prevalence of Toxocara eggs in the sand in children's playgrounds in Frankfurt/M. Ann Trop Med Parasitol 1984, 78(6):633-636.

19. Shimizu T: Prevalence of Toxocara eggs in sandpits in Tokushima city and its outskirts. Vet Med Sci 1993, 55(5):807-811.

20. Santarem VA, Sartor IF, Bergamo FMM: Contamination by Toxocara spp. eggs in public parks and squares in Botucata, Sao paulo state. Brasil Rev SocBrasileira Med Trop 1993, 31(6):529-532.

21. Loh AG, Israf DA: Test on the centrifugal flotation technique and its use in estimating the prevalence of Toxocara in soil samples from urban and suburban areas of Malaysia. J Helminthol 1998, 72(1):39-42.

22. Zamora K, Garcia DR, Dark Vicente Diaz L: Toxocara spp. in parks and public zones of city of Havana 1995. Cuba Rev HigEpide- Miol 2000 38(2):112-116

23. Dada BJO, Lindquist WD: Prevalence of Toxocara spp. eggs in some public grounds and highway rest areas in Kansas. J Helminthol 1979, 53(2):145-146

24. Güre FS, Ertug S, Okyay P: Prevalence of Toxocara spp. eggs in public parks of the city of Aydin, Turkey. TurkiyeparazitologiDergist 2005 29(3):177-179.

25. Mahdi NK, Ali HA: Toxocara eggs in the soil of public places and schools in Basrah, Iraq. Ann Trop Med Parasitol 1993, 87:201-205.
26. Gillespie SH, Pereira M, Ramsay A: The prevalence of Toxocaracanis ova in soil sam- ples from parks and gardens in the Londonareas. Public Health 1991, 105:335-359.

27. Holland C, O'connor P, Taylor MR, Hughes G, Girdwood RW, Smith H: Families, parks, gardens and Toxocariasis. Scand J Infect Dis 1991, 23(2):225-231

28. MR R d y, Garijo MM, Alonso FD: Prevalence and viability of eggs of Tox- ocaraspp.andToxascarisleonina in public parks in eastern Spain. J Helminthol 2001, 75(2):169-173.

29. Khazan H, Khazaei M, Seyedtabaei SJ, Mehrabi A: Prevalence of ToxocaraSpp, eggs in Public Parks in Tehran city, Iran. Iran J Parasitol 2012, 7(3):38-42.

30. Maraghi S, Rafiei A, Hajhosein R, Sadjjadi SM: Sero- prevalence of toxocariasis in hypereosinophilic individuals in Ahwaz, South- western Iran. JHelminth 2011, 86(2):241-244.

31. Talaizadeh AH, Maraghi S, Jelowdar A, Peyvasteh M: Human toxocariasis: a report of 3 cases. Pak J Med Sci 2007, 23(5):782-784.

32. Sadjjadi S, Oryan A, Jalai A, Mehrabani D: Prevalence and intensity of infestation with Toxocaracati in stray cats in Shiraz, Iran. Vet Archiv 2001, 71(3):149-157.

33. Mehrbani D, Sadjjadi S, Oryan A: Prevalence of gastrointestinal nematode parasites in stray dogs in shiraz, southern iran. J ApplianimResea 2002, 22(1):157-160.

34. Arbabi M, Hooshyar H: Gastrointestinal parasites of stray cats in Kashan, Iran. Trop Biomed 2009, 26(1):16-22.

\section{doi:10.1186/2052-336X-12-86}

Cite this article as: Maraghi et al.: Study on the contamination of Abadan public parks soil with Toxocara spp. eggs. Journal of Environmental Health Science \& Engineering 2014 12:86.

\section{Submit your next manuscript to BioMed Central and take full advantage of:}

- Convenient online submission

- Thorough peer review

- No space constraints or color figure charges

- Immediate publication on acceptance

- Inclusion in PubMed, CAS, Scopus and Google Scholar

- Research which is freely available for redistribution 